\title{
Philosophical Root of Moderation Discourse in Iran's Eleventh Presidential Election
}

\author{
Leila Jafari \\ PHD Student, \\ Faculty of Administrative Sciences and Economics, \\ Department of Political Science, University of Isfahan
}

Ali Alihosseini

Associate Professor,

Faculty of Administrative Sciences and Economics, Department of Political Science, University of Isfahan

Corresponding Author

\section{Seyyedjavad Emamjomehzadeh}

Associate Professor,

Faculty of Administrative Sciences and Economics, Department of Political Science, University of Isfahan

Doi: $10.2478 / \mathrm{mjss}-2018-0014$

\section{Abstract}

Moderation was a triumphant discourse of Iran's eleventh presidential election. It's a new attitude in the political realm and most of the movements relate themselves to it and each one interprete their actions according to moderation. For clarifying this ambiguous trend, we should refer to its philosophical root. It seems that Aristotle is the first one who represented this theory. In fact, moderation is one of the main principles of Aristotelian ethics. Understanding this concept requires understanding the basic concepts of the intellectual and moral theory of Aristotle. Moderation is the center of his theory of virtue. According to this principle, all the moral virtues are intermediates and excess, and defects in the actions and emotions cause moral vices. This theory could be the best way to pass excess and deficiencies in Iran's political sphere.

Keywords: Aristotle's ethics, moderation, virtue, excess, deficiency

\section{Introduction}

Different discourses were dominant in the political realm of Iran after the Islamic Revolution; each had its own domestic policy and foreign diplomacy. Moderation as a political terminology entered to Iran's political literature in the eleventh presidential election. In the period after the election, moderation signifier has taken different meanings among different discourses of Iran's intellectual sphere such as moderation in the meaning of escaping from the fundamentalism and reformism, in the meaning of moderate fundamentalism, in the meaning of conservative reformism, and also in the meaning of rational approach against extremism. It seems that various political groups in Iran have tried to put this term and its emerged political and social parties in one of those formats. To understand the true meaning of the term 'moderation' we have to refer to its philosophical roots. Therefore the meaning of this term will be examined in the political and ethical philosophy of Aristotle, who is the first person represented it. 
It goes without saying that the political goals of philosophy revolve around the fundamental question how the hypothetical government should act in any society. What ethical principles should be regranted on its behavior with its followers? And what kind of political order is trying to be established, in an ideal sense. Thoughts and ideas of Aristotle can be considered as one of the earliest analyzing and describing examples of ethical principles of hypothetical government. The ideas of Aristotle are often reported in the form of a descriptive summary in "Politics" and "Nicomachean Ethics" books. Aristotle's moral philosophy and particularly his moderation theory are considered as a part of his theories. We think that his moderation theory is an inevitable consequence of ontology, anthropology, ethics and customs of Greece. So, for understanding this theory we have to refer to the history of his intended ideas and concepts in his Nicomachean Ethics book.

\section{Methodology}

Moderation was a triumphant discourse of Iran's eleventh presidential election. Our question is that what is the philosophical root of Iran's eleventh presidential election? This article has hypothesized that Aristotle moderation theory could explain the triumph of this discourse. Our Purpose is to discover the philosophical root behind Iran's eleventh presidential election, using descriptiveanalytical method and referring to Aristotle ethics. Results indicate that Aristotle's concept of moderation can be a way to fill in the gaps between extremist sides in Iran's society.

\section{History of Aristotle's Moral Philosophy in "Politics"}

Expounding his political philosophy in Politics, Aristotle states that family is created by joining people together. The village is, in turn, created by gathering families, and finally by gathering villages together the city-state is created. All of these categories are general and have a "goal" according to the natural universal model. Self-sufficiency in supplying requisites is the goal of each of these smaller communities which are met in the city-state. So, the city-state is the goal of individual, family and village, and they achieve the goal of self-sufficiency by joining city-state. Based on this natural universal model, the created city-state, as a material, is the prowling of practicality (Zolhassani, 2006: 93). The ultimate goal and face of this city-state is the happiness of the community which means that life is based on virtue, and justice is the supreme end of the citystate and organizer the political community.

Aristotle regards city-state as a great man in which every class of society is part of its body and plays a role to its perfection. The happiness of this city-state depends on principles of individual happiness for everyone's sample of happiness determines the happiness of the city-state. As man is composed of body and soul, and soul composed of wisdom and lust, the city-state is forgathered from various classes, and these classes are not equal from point of view of virtue. This body is a virtue when all of its members do their duties well; this means that each one enjoys its own special virtues (Zolhassani, 2006: 94). Then in "Nicomachean ethics" he tries to describe man's happiness and virtue and the way of achieving them in order to provide virtue and happiness in the city-state.

Unlike his preceptor Plato, Aristotle is not in the wake of the supreme good and divine morality, rather he wants to develop terrestrial ethic according to terrestrial rules and laws available to all. So, he draws the framework of true ethic with simple and familiar words, means that every human being at any point of time, place, and position can be ethical and happy along with it. Aristotle wants to explain why and how a person should live. He further explains how a society should be formed to provide the feasibility of such life (Gerard, 2001: 13).

The subject of Aristotle ethics is the man and his behavior, which has complex nature and behavior that makes it very difficult to understand. Overall, for Greek people a man without a city does not make sense, and if one wants to study human being, they must consider him as a citizen rather than as an abandoned individual. This politic or art of statecraft involves ethics because the happiness and welfare of the state and society comprise individual's welfare (Gemprts, 1996: 1469). So Aristotle's study of human happiness and behavior are not done regardless of state and societies' happiness. He never contemplates researching human's good regardless of policy and apart from society's good study (Taylor, 1995: 90). 


\section{Explaining the Philosophy of Aristotle's Ethics}

Aristotle's discussion of ethical philosophy begins with the concept of "goal" and continues with the goal of human life. This goal is the same as "good". So, he deals with practice in ethics- a practice that leads human to good. In order to achieve good (goal) every action is correct and whatever is in contrary to achieving this good is erroneous and wrong. This is stated in early phrases of 'Nicomachean Ethics': "The general idea is that every art and every scientific and theoretical investigation and any action and selection, is focused on the good. Well said, it is good that everything tends toward it" (Aristotle, 1094 a). In fact, Aristotle's scale for supreme good expressed in this way that when $A$ have done because of the $B$ ( $B$ is the ultimate act of $A$ ), then, $B$ is better than A. However, there is a goal that we want it for itself and all other goods or subsidiary goals are for this supreme end. This good is the supreme good. So, we should reach a definite supreme good in the hierarchy of goods, and it must be a good for human; the same thing which Aristotle expressed as his origin and starting point in the discussion about ethic (Aristotle. 1098b).

What is this human good which is the goal of his life? Here, Aristotle accepts the "public" view that this goal (good) is "Eudaimonia", which often translated into happiness and well-being (Aristotle, 1095 b). Therefore, happiness is the goal of human's life which includes both features considered by Aristotle: firstly, it is supreme; this means something that can be chosen for itself and not an instrument for something else. Secondly, it is self-sufficient; that means it could make it valuable per se for somebody that has chosen it (Ross, 1995: 292). Aristotle then adds that there are two kinds of happiness:

A) Eudaimonia or happiness which has positivistic aspect, in the sense of pleasure, wealth, and honor. B) The whole or healthy human soul.

Now the next question raised is that what happiness is. Aristotle's enumerates three kinds of life to answer this question: animal, human and divine life. Lust is dominant on the person at the first life, the practical reason is dominant on the second life and the theoretical reason is dominant on the third life. According to Aristotle, these three types of happiness are arranged in chronological order. It means that every person often achieves animal happiness at first in his growth process, and then if he trained properly and get used to what he learned from the training, he will achieve human one. And finally, he could find the divine happiness.

Happiness is the same as pleasure in animal life because the lust is dominant power in it. Animals other than humans have this too. This pleasure is enjoying of eating, drinking and sexual relations. Animal pleasure prevails the man at least until the young hood (Aristotle, 1095 a6-10). Aristotle believes that most people don't go beyond animal pleasure as happiness throughout all their lifetime. Hence, to improve human beings to get to higher levels, it is necessary to educate them. The purpose of this training is to make them enjoy what is good and suffer from what is not. The good for human is happiness (Aristotle, 1097b). Happiness is an activity in accordance with virtue, and if there are multiple virtues, it's in accordance with the best and most complete ones. Human happiness reaches its perfection by practical reason, and in this situation, a person will have the entire virtuous mood and will act in accordance with them from Aristotle's point of view. One is ready to enjoy the theoretical verbs just after such transformation. Therefore, someone who has reached this stage is virtual, which means he has acquired virtuous mood and acts in this way; and according to Aristotle's definition, he has reached human happiness.

$\mathrm{He}$ pointed out that the happiness is the attainment of virtue that comes with activity, therefore; according to Aristotle, achieving the virtue without acting and in a manner that does not end up good is not happiness (Aristotle, 1098b, 1099a).

On the other hand, Aristotle states that human's supreme good (happiness) plays the role of an element from the soul which belongs particularly to human. Being human which means being able to do a certain kind of activity is the consequence of seasonal source. So, his well-being depends on playing this role well. In ancient Greece, virtue was not something that belonged only to an ethical sphere or one that was necessarily acquired, but any advantage granted by God in the person was called virtue. The manifestation of the virtue of something appears when it performs efficiently its duty according to world order created by Zeus. (Saifullahi, 2010: 32).

Because human-specific component (compared to animals) is his reason. His special 
activities also agree with this reason and this is really a virtue. So, happiness is synonymous with behavior based on the best and most complete virtues throughout life (Aristotle, $1098 \mathrm{a}$ ). In the completion of virtue definition, Aristotle adds: "virtue is a medium mood that causes free choice in practice and recognizes all the means for us by reason or a wise man.

In fact, virtue is the virtue of practical wisdom and this virtue is a kind of mediocrity in terms of its existence nature. This means, it always tends to moderate and can identify in a few cases and variables limits of moderation and mediocrity and choose correct moderate behavior.

So, the gist of virtue in the sense of intermediates is that reaching practical wisdom and practical wise man is in the moderate and mediocre situation, and this virtue is at the peak of perfection. Such moderation is not comprising excess and deficiency, rather it is absolute virtue and stable and firm perfection of the human soul; a virtue that makes a man and subsequently his specific actions good and moderate (Aristotle, 1106 a)

\section{Moderation in Aristotle's Ethics}

Aristotle believes that with moderation in all things in life, the happiness which is the goal and purpose of morality will be obtained. Happiness would not be achieved by certain activities and efforts, however; it is an expression such as the insistence that should be realized in intraoperative and behavior, not a goal to be achieved. Happy and good life according to Aristotle is similar to eating well. If the question is how much one should eat per day to be feed properly, Aristotle replies that in this regard, there is no general answer for defining specific amount. The amount depends on the size, height, weight and work status of the person. It is clear that the obese person needs more food than a skinny one. Everyone should comply with moderation between bulimia and anorexia according to his own situation. In fact, Aristotle thinks that moderation is the way of attaining to happiness. He states that virtue or ethics is the moderation between excess and deficiency. He believes every mood has a certain level which more or less than that what is a vice, but that mood in itself is a virtue. Aristotle do not confine this overall statement, applies it to individual cases and partial deals the same as what David Ross did in the following table (Ross, 1995: 307).

Table1: (Ross, 1995: 307)

\begin{tabular}{|c|c|c|c|c|}
\hline Deficiency & Moderation & Excess & Action & Feeling \\
\hline No special name & Courage & Cowardice & & the fear \\
\hline Cowardice & Courage & Impetuosity & & Self Confidence \\
\hline \multirow[t]{2}{*}{ Numb } & Chastity & Debauchery & & Some tactile pleasures \\
\hline & & & & $\begin{array}{l}\text { Stems from a desire to } \\
\text { such pleasures }\end{array}$ \\
\hline $\begin{array}{l}\text { Stinginess } \\
\text { Profusion }\end{array}$ & Generosity & $\begin{array}{l}\text { Lavish (spendthrift) } \\
\text { Avarice (Fasting) }\end{array}$ & $\begin{array}{l}\text { Giving money } \\
\text { receiving money }\end{array}$ & \\
\hline Forgiveness & Penny & $\begin{array}{l}\text { Giving testimony to a } \\
\text { populist }\end{array}$ & $\begin{array}{l}\text { Giving money to large } \\
\text { scale }\end{array}$ & \\
\hline Humility & Self-esteem & Boasting & $\begin{array}{l}\text { Demands a great } \\
\text { honor }\end{array}$ & \\
\hline No cause & $\begin{array}{l}\text { No special } \\
\text { name }\end{array}$ & Ambitions & Search proud to heap & \\
\hline $\begin{array}{l}\text { The lack of power } \\
\text { wrath }\end{array}$ & Gently & Spicy humor & & Anger (rage) \\
\hline $\begin{array}{l}\text { Inferiority } \\
\text { complex }\end{array}$ & Truth telling & Bounce (boasting) & $\begin{array}{l}\text { Telling the truth about } \\
\text { themselves }\end{array}$ & Social interactions \\
\hline Indecorous & $\begin{array}{l}\text { Telling jokes } \\
\text { (humor) }\end{array}$ & $\begin{array}{l}\text { Ribbing } \\
\text { (contamination) }\end{array}$ & $\begin{array}{l}\text { Bring happiness to } \\
\text { others without profit }\end{array}$ & \\
\hline $\begin{array}{l}\text { Acidic } \\
\text { (misbehavior) }\end{array}$ & $\begin{array}{l}\text { Friendship } \\
\text { (help) }\end{array}$ & Flattery (flattering) & $\begin{array}{l}\text { Bring happiness to } \\
\text { others for profit }\end{array}$ & \\
\hline Without shame & Modesty & Shyness & & Shame \\
\hline Ill-wisher & $\begin{array}{l}\text { Resentment } \\
\text { behind }\end{array}$ & Jealously & & $\begin{array}{l}\text { Suffering caused by the } \\
\text { happiness or misery of others }\end{array}$ \\
\hline
\end{tabular}




\section{The Concept of Intermediates can be Investigated in Two Areas:}

Mediocrity means achieving the perfect virtues (practical wisdom) and reaching an internal balance and harmony. Moderation is a general rule, a practical and training solution in relation to the actions and feelings to achieve true virtue. This true virtue leads a person into true mean by determining the limits of excess and deficiency of actions and feelings.

Since achieving mediocrity is difficult according to Aristotle and in order to determine it we should be wise or emulate practical sages, in each society, practical sages must be trained to study and carefully evaluate all the factors relevant to the situation. They must recognize minor mediocrity in variable conditions (Qureshi et al, 2010: 185). According to Aristotle, the reason of moderation is that people adore moderate person and blame extreme and deficiency (Aristotle, $1115 \mathrm{a}$ ).

Aristotle is aware of the fact that since the extreme and deficiency are two quantitative notions, moderation rule should be used in matters of quantity. However, for qualitative matters, Aristotle used moderation rule in a different way in which moderation is in the sense of "proportionality" and "balancing" of an act according to the situation; that is, to act in "right way".

Aristotle mentions several qualitative criteria that the moral agent must apply them in his feelings: 1. Field time, 2. Field subject, 3. Field person, 4. Field cause and motivation, 5. Field method and size (Aristotle, 1125b). The constraint used by Aristotle clearly indicates that moderation criterion is not a quantitative criterion, and we should note the quality of our emotions and feelings, as well. It seems that the addition of the word "Field " to different dimensions of the act, shows that from Aristotle's point of view "field limit" could be a substitute for "moderation" and "mediocrity".

So, the concept of moderation has both positive and negative meanings. In positive one, the person should choose the right action by using wisdom which necessitates various acts according to time, place and situations.

In the negative notion, we should first figure out what are excess and deficiency. In other words, before we could say what moderation is we should clarify what moderation is not.

\section{Moderation in Social and Politic Sphere}

In the realm of policy also moderation means mediocrity. Based on the intellectual, cultural, economic, and political imbalances, moderation can be determined as equilibrium point between these excess and deficiency such as:

Individualism- Collectivism

Integrity- pluralism

Benefit centrism- security centrism

Religious- secular

Stability (positivist and Fundamentalist) - transformation (evolution of demand and reformist)

Freedom- control

Centralized political system- liberal system

Globalization- native (independence and return to self)

Tend to west- tend to the East

Traditionalism- modernism

Dependence- independence

Free market- controlled economy

Centralization- decentralization

Institutionalism- individualism

Expansion- distribution

Republic- Islamic

Nationalism- localism

National- religious

Scientism- religious minded

Authoritarian regime- democracy

State centrism- civil society driven

Political development- economic development 
According to the special feature of Iranian society, often a tendency to these extremes which are located at the ends of the spectrum have been very effective (Hajiyani, 2014:102). This situation has been influential among state and official elites, civil society organizations, and intellectuals as well.

What is clear is that the lack of moderation in behavior imposes very heavy costs on society. According to many psychologists and sociologists, roots of anarchist phenomenon in the community come back to the lack of attention to rationality. Lack of attention to social moderation leads society to anarchism and classical liberalism (Kharrazi, 2013). The tendency to extreme behave in the Islamic republic period certainly has caused a lot of damage in political, cultural, and diplomatic fields.

In the domestic arena, sometimes social justice is important, in another time political development attracts special attention, and in some other time, economic development becomes an important issue. In cultural debates, approving or rejecting the orders and rules of Islamic culture and religion from citizens, the interference of the government and Islamic state in cultural affairs of the society and people, adhering to the part of the religious orders and disregarding the other parts are examples which encountered with numerous extremes.

In the area of diplomacy, there has not been a balance between idealism and realism and much attention has been paid to one of these two approaches at different times. Therefore, more or less emphasis has been put to pursue the national and international goals. The interests of Islam and national interests have been confused. There has not been a balance for estimating the national power and defining its objectives by appropriate means.

According to Aristotle, for passing the excess and deficiency we should find a moderate way between them according to our wisdom. The concept of moderation can be a way that fills the gaps in extremist ways. Excess means to deny everything in the culture of the 'other' and deficiency means to absolute surrender against it. So, moderation is a virtue that meant by taking the advantages of these two limits. Therefore, one of the indicators of moderation in domestic politics is lack of violence, patience, human rights, and tolerance for opposition.

\section{Conclusion}

Moderation entered to Iran's political terminology after the eleventh presidential election. Its philosophical root goes back to Aristotle moderation theory. To clarify this theory, it is necessary to briefly express his ethical system. He believes that what man does is always for achieving good; human favorable goals have degrees, and happiness is the absolute goal.

But human happiness is achieved when he achieves virtue. Virtue is achieved when the person does his provided task in the best way. The task appointed to the man that distinguishes him from other creatures is his soul and mind harmonic activity, and this harmony provides happiness and virtue for him. The criterion of virtue and the way to achieve it is to observe it in all affairs, which is the mean between the two sides or the moderation between the two extremes of excesses and deficiencies. Aristotle believes that moderation in everything provides happiness for man. This theory could be a very useful way to pass excess and deficiency in Iran's political sphere.

\section{References}

Aristotle (2009). The Nicomachean Ethics, Trans. David Ross, Oxford University Press, Oxford.

Gemprts, T. (1996). Greek thinkers, Volume III, translated by Mohammad Hassan Lotfi, First Edition, Tehran, alKhwarizmi

Gerard, H.J. (2001), Aristotle on Ethics, Routledge, New York.

Hajiyani, E. (2014). Approach on moderation dialogue, Tisa, Tehran

Kharrazi M.S. (2013). Moderation and politics. Students of the Imam's Line Media News analysis.

Qureshi, M., Zahra, M. and Ghasem, A.k (2010). Explanation of mediocrity in Aristotelian ethics, new religious ideas, Volume 6, Number 20

Ross, D. (1995). Aristotle, Taylor \& Francis, 6th Edition

Saifullahi, F. (2010). Mediocrity in Aristotle's ethics, Master's thesis, University of Tabriz.

Taylor, A.E. (1995), Aristotle, Dover, New York.

Zolhassani, F. (2006). Principles of the theory of justice, Aristotle, Avicenna's Philosophy, fall, Number 34 